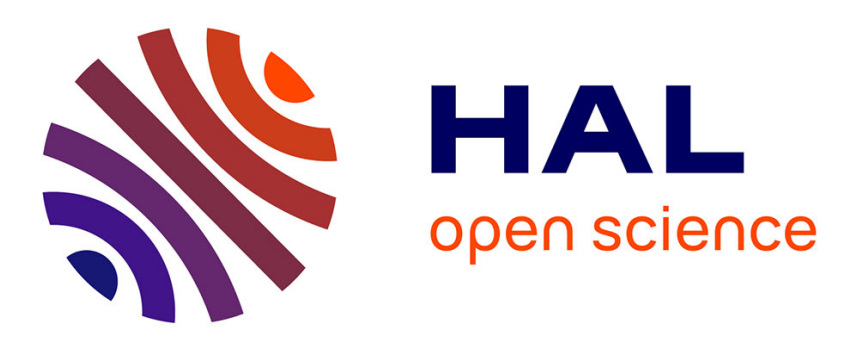

\title{
Continuum mechanical modelling of the dissipative processes in the sediment-water layer below glaciers
}

Francesco Dell'Isola, Kolumban Hutter

\section{To cite this version:}

Francesco Dell'Isola, Kolumban Hutter. Continuum mechanical modelling of the dissipative processes in the sediment-water layer below glaciers. Comptes rendus de l'Académie des sciences. Série 2, 1997, pp.8. hal-00501516

\section{HAL Id: hal-00501516 https://hal.science/hal-00501516}

Submitted on 15 Jul 2010

HAL is a multi-disciplinary open access archive for the deposit and dissemination of scientific research documents, whether they are published or not. The documents may come from teaching and research institutions in France or abroad, or from public or private research centers.
L'archive ouverte pluridisciplinaire HAL, est destinée au dépôt et à la diffusion de documents scientifiques de niveau recherche, publiés ou non, émanant des établissements d'enseignement et de recherche français ou étrangers, des laboratoires publics ou privés. 


\section{Continuum mechanical modelling of the dissipative processes in the sediment-water layer below glaciers}

Francesco dell'ISOLA and Kolumban HUTTER

F. dell'I.: Dipartimento di Ingegneria Strutturale e Geotecnica, Lniversità di Roma La Sapienza, Via Eudossiana 18, I-00184 Rome, Italy;

E-mail : isola@scilla.ing.uniroma1.it

K. L.: Institut für Mechanik Tech. Hochschule Darmstadt, D-64289 Darmstadt, Germany.

Abstract. The solid mass of the saturated viscous, heat-conducting sediment-water layer below temperate glaciers grows by abrading the underlying rockbed. We propose to model this layer as a saturated mixture continuum of fluid and solid. We formulate its balance laws in volume and jump local forms following, e.g. Germain and Muller (1986). The water balance accounts for its drainage into the rockbed and the melting of ice within the overlaid ice sheet. Dissipation due to the power expended by stresses, the Darcy interaction force and sliding friction governs this thermomechanical system. Our analysis establishes that, contrary to what is stated in the literature, the listed dissipative mechanisms are all relevant.

Keywords: continuum theory of mixtures / dissipation in till layers

Modélisation en mécanique des milieux continus des phénomènes de dissipation dans la couche sédimentaire saturée d'eau au-dessous des glaciers

Résumé. Nous proposons d'utiliser la théorie axiomatique des mélanges pour modéliser la couche de sédiments rocheux saturée d'eau au-dessous des glaciers (lit souple). Dans cette couche: la masse sédimentaire est accrue par abrasion du lit rocheux séparé du glacier par elle; la masse d'eau est changée par la fusion dans le glacier au-dessus et par le drainage à travers le lit rocheux; il y a propagation de la chaleur. On formule des lois de conservation et de comportement et on trouve les équations aux dérivées partielles et aux discontinuités associées, voir Germain et Muller (1986). On montre que, dans le lit souple, contrcirement à ce qui est admis dans la littérature (Alley et al., 1987a,b; MacAyeal, 1992), les énergies dissipées à cause de - au moins - cinq phénomènes différents sont comparables.

Mots clés : théorie axiomatique des mélanges / dissipation dans le lit souple des glaciers 


\section{F. dell'Isola and K. Hutter}

\section{Version française abrégée}

Parmi les problèmes que l'on rencontre dans l'étude des phénomènes de désintégration des glaciers dans la partie occidentale de la région Antarctique, celui qui est peut-être le plus important, concerne la détermination de l'importance relative des différents mécanismes de dissipation, qui ont lieu dans la couche sédimentaire saturée d'eau (lit souple) qui sépare le glacier de son support rocheux, aussi dit lit rocheux ou lit dur. Dans la littérature, des efforts remarquables ont été faits pour analyser ce problème (Mac Ayeal, 1992), mais jusqu'à présent, il n'y a pas, à notre avis, d'analyse complète des phénomènes thermodynamiques complexes qui ont lieu dans le lit souple. Dans cette note, on se propose de modéliser le lit souple, dans le cadre de la théorie axiomatique des mélanges (e.g., Truesdell, 1969), comme un mélange de composants solide isotrope (la masse sédimentaire) et liquide (l'eau), tous deux incompressibles, visqueux et conducteurs de chaleur. Cette possibilité d'application de la théorie des mélanges n'a, semble-t-il, jamais été envisagée précédemment. Pour le milieu continu considéré, on formule séparément les lois de conservation de la masse et de la quantité de mouvement pour les deux composants, et celles de l'énergie de l'ensemble du mélange (pour une discussion détaillée des conséquences thermodynamiques de cette hypothèse de travail, Truesdell, 1969) et on l'ajoute les lois de comportement qu'une analyse phénoménologique précédente (Vulliet et Hutter, 1988 ; Svendsen et Hutter, 1995) a déterminé comme des plus adaptées à la description du lit souple au-dessous des grands glaciers. Puisque les champs de vitesse dans la couche sédimentaire sont très petits (voir la discussion quantitative dans la dernière section), on a négligé toute puissance de la vitesse supérieure à la première dans les lois de conservation et de comportement quand elle est comparée à des quantités plus importantes (ce qui n'arrive que dans les équations (11) et (14)). Dans les deuxième et troisième sections, en employant la méthode exposée par exemple par Germain et Muller (1986), on trouve les équations aux dérivées partielles et aux discontinuités associées aux lois de conservation et de comportement. Les équations aux dérivées partielles sont valables à l'intérieur de la région occupée par la couche sédimentaire, tandis que celles aux discontinuités sont valables aux frontières de la couche avec le glacier au-dessus et le lit de roche au-dessous. Pour compléter la formulation mathématique du modèle, il faut finalement ajouter les équations cinématiques pour les deux frontières citées. Ces équations s'étayent physiquement sur les observations suivantes : la masse sédimentaire n'est accrue que par l'abrasion du lit (dur) rocheux et la frontière commune de la couche et du glacier est imperméable pour le sédiment; la couche est définie comme la région «spatiale » occupée par les sédiments rocheux détachés par abrasion du lit (dur) rocheux; le mouvement du lit de roche peut-être déterminé si l'on connaît l'épaisseur du glacier qui est soutenu par le lit même. Le problème mathématique ainsi formulé est un problème à frontière libre pour un système d'équations aux dérivées partielles qui paraît novateur et donc, mériterait une étucle mathématique soigneuse. Pour évaluer la capacité prédictive du modèle proposé, ce problème sera étudié à l'aide d'une analyse numérique (dell'Isola et Hutter, 1997). Néanmoins, on peut analyser les équations obtenues, et en particulier, celles qui représentent la loi de conservation de l'énergie, pour déterminer et comparer l'ordre de grandeur des différents mécanismes de dissipation qui sont considérés dans le modèle proposé. Dans la dernière section, cette analyse est effectuée : on emploie les valeurs connues des constantes physiques utilisées dans le modèle développé et des estimations de toutes les quantités qui caractérisent le processus «mouvement d'un grand glacier sur son lit dur lié aux changements climatiques ». Clairement, les valeurs des estimations appartiennent à une plage et par conséquent on parvient aussi pour l'énergie dissipée par chacun des mécanismes considérés à une plage de valeurs. Le résultat - à notre avis - le plus intéressant obtenu à travers la modélisation proposée consiste à montrer que : i) l'énergie dissipée par la force d'interaction à la Darcy entre les constituants, ii) la puissance développée par les efforts intérieurs dans le mouvement du mélange, iii) l'énergie dissipée à cause du frottement dans le glissement du glacier sur la couche, iv) l'énergie dissipée dans le glissement de la couche sur le lit dur 
Continuum modelling of sediment water below glacier

et à cause de l'abrasion de roche du lit dur, v) la chaleur latente produite par la fusion de la glace à la frontière entre la couche et le glacier, ont des ordres de grandeur comparables.

\section{Introduction}

Solid rock or a layer a few metres thick consisting of sediments (till in glaciological jargon) saturated with water form the so-called hard and soft beds of large ice sheets. The large velocities observed in ice stream B of Antartica and the conjectured disintegrations in the distant past of the West Antartic Ice Sheet are attributed to the thermomechanical behaviour of the till layer, but, to date, a convincing thermomechanical theory of the physical process arising in the soft layer does not exist, see Alley $e$ if al. (1987a,b), MacAyeal (1992) and Svendsen and Hutter (1995).

In this paper we propose to model the till layer as a saturated mixture of an isotropic, incompressible, viscous, heat-conducting solid and an incompressible, viscous, heat-conducting fluid.

For an exhaustive (and already classical) presentation of the axiomatic theory of mixtures that we use here, we refer to Truesdell (1969). To be precise we use a generalized version of classical mixture theories: we postulate two balance equations for mass and force (one for each mixture component) but only one balance of energy for the mixture as a whole. In Truesdell (1969) the mathematical and thermomechanical implications of such an assumption are discussed: in particular it is proven that only one energy balance law, in the form we use in the present paper, is suitable to describe mixtures in which both components have, at the same place and at the same instant, the same temperature. This is exactly the case in the till layer whose model we are looking for.

Generalizing the reasonings developed in Vulliet and Hutter (1988) to the example considered here, we assume that the shear viscosity of the solid is given by a power law, that of the fluid is constant, and the interaction force contains a Darcy term that is linear in the relative velocity of the constituents. Apart from this, the stresses and the interaction force have equilibrium contributions involving the saturation pressure, a variable maintaining the saturation constraint, and a thermodynamic pressure derivable from the free energy, as shown by Svendsen and Hutter (1995).

The boundary conditions at the top interface, between the temperate ice and the till layer, and at the bottom interface, between the till layer and the rock bed, both involve the kinematic equations, describing their evolutions, and the jump conditions obtained by the balance of mass, momenta and energy. These jump conditions incorporate the mass flow of moisture from the temperate ice above and the melting of ice at the top interface together with the drainage of water from the till layer into the rockbed and the abrasion of till from the hard rockbed at the bottom interface. Dissipation due to sliding at the interfaces and to the energy flux and stress powers within the layer is very important: it determines the amount of ice that is melted. The water drawn into the layer and the till abraded from the rockbed determine, together with the saturation pressure, the volume fraction of sediment and thereby the thickness and the mobility of the sediment layer and consequently the overall horizontal velocity, as lower kinematic boundary condition, of the ice sheet above it. This velocity is the main variable determining the stability or disintegration of the ice sheet.

The aim of this paper is manifold:

(1) to find a new application for the axiomatic theory of mixtures, introducing a model for the till layer below glaciers;

(2) to establish, contrary to what is stated in the literature, that several dissipative mechanisms occur in the till layer and are together all relevant; 


\section{F. dell'Isola and K. Hutter}

(3) to formulate a new free moving boundary problem describing the time evolution of the till layer;

(4) to motivate the need for more sophisticated models to describe the thermomechanical behaviour of till layers: the formulation of such a model will be attempted in dell'lsola and Hutter (1997).

\section{Field equations}

Based on Svendsen and Hutter's (1995) thermodynamic formulation of the axiomatic theory of mixtures (Truesdell, 1969), we propose a mixture model for till layers constiting of viscous, heatconducting solid-fluid constituents. It is given by the following balance equations (the upper dot denoting material time derivative with respect to the fictious barycentric velocity)

$$
\begin{gathered}
\frac{\partial \rho_{a}}{\partial t}+\operatorname{div}\left(\rho_{a} \mathbf{v}_{a}\right)=0, \operatorname{div} \mathbf{T}_{a}+\mathbf{m}_{a}=0 \quad(a=f, s) \\
\rho \dot{\varepsilon}=-\operatorname{div} \mathbf{q}+\operatorname{tr}\left[\left(\sum_{a} \mathbf{T}_{a}\right)\left(\sum_{a} \xi_{a} \mathbf{D}_{a}+\operatorname{sym}\left(\operatorname{grad} \xi_{a} \otimes \mathbf{v}_{a}\right)\right)\right]
\end{gathered}
$$

and is completed by the following constitutive equations (discussed in a slightly different context by Vulliet and Hutter (1988) and fully justified from the thermodynamic point of view by Svendsen and Hutter (1995)):

$$
\begin{aligned}
& \mathbf{T}_{s}=-v(-\beta v+p) \mathbf{I}+\left(A_{s}\right)^{\frac{1}{n}}\left(I I\left(\mathbf{D}_{s}^{\prime}\right)\right)^{\frac{n-1}{2 n}} \mathbf{D}_{s}^{\prime} \\
& \mathbf{T}_{f}=-(1-v) p \mathbf{I}+\mu_{f} \mathbf{D}_{f}^{\prime} \\
& \mathbf{m}_{s}=-\mathbf{m}_{f}=\left[p+\left(1-\xi_{s}\right) \beta_{s}\right] \\
& \varepsilon=\sum_{a} \xi_{a} \varepsilon_{a}=\left(1-\xi_{s}\right) \varepsilon_{f}\left(\vartheta_{0}\right)+\xi_{s} \varepsilon_{s}\left(\vartheta_{0}\right)+\left[\left(1-\xi_{s}\right) c_{f}+\xi_{s} c_{s}\right]\left(\vartheta-\vartheta_{0}\right) \\
& \mathbf{q}=-\left(k_{f}+k_{s}\right) \operatorname{grad} \vartheta-\sum_{a}\left(\mathbf{T}_{a}^{T} \mathbf{u}_{a}-\rho_{a} \varepsilon_{a} \mathbf{u}_{a}\right)
\end{aligned}
$$

where

$$
\left\{\beta, \mu_{f}, A_{s}, n, m_{d}, \varepsilon_{a}\left(\vartheta_{0}\right), c_{a}, \vartheta_{0}, k_{a}\right\} \text { are constants, }
$$

and the following denotations are used

$$
\begin{gathered}
\rho_{a}=v_{a} \hat{\rho}_{a}, \rho=\sum_{a} \rho_{a}, \quad v_{s}=v, \quad \mathbf{v}=\frac{1}{\rho} \sum_{a} \rho_{a} \mathbf{v}_{a}, \quad \mathbf{u}_{a}=\mathbf{v}_{a}-\mathbf{v} \\
\xi_{a}=\rho_{a} / \rho, \mathbf{D}_{a}=\operatorname{sym} \operatorname{grad} \mathbf{v}_{a} \quad \forall \mathbf{S}\left(\boldsymbol{I I}(\mathbf{S}):=\frac{1}{2} \operatorname{tr}\left(\mathbf{S}^{2}\right),(\mathbf{S})^{\prime}:=\mathbf{S}-\frac{1}{3}(\operatorname{tr} \mathbf{S}) \mathbf{I}\right)
\end{gathered}
$$

We explicitly remark that the previous equations are obtained from those valid for a generic mixture (see Truesdell (1969) for more details) when neglecting 


\section{Continuum modelling of sediment water below glacier}

(1) material derivatives of kinetic energy and inertial forces expressed in terms of powers (of order higher than one) of the velocity fields with respect to stress power and divergence of stress, respectively;

(2) volume forces with respect to divergence of stress.

This hypothesis seems to be well-grounded from the physical point of view (see Alley et al.,1987a,b) and will become more evident in the last section.

Equation (1) together with the definitions (4), the constitutive relations (2) and the physical constants (3) form nine non-linear partial differential equations for nine independent fields $v, p, \mathbf{v}_{a}(a=f, s$, characterizing the fluid and the sediment, respectively) and $v$.

In the above, $\rho_{a}, \hat{\rho}_{a}, \rho, v_{a}$ are, respectively, the constituent densities, constituent true densities, the mixture density and the constituent volume fractions; $\mathbf{v}_{a}, \mathbf{v}, \mathbf{u}_{a}, \mathbf{D}_{a}$ are the constituent velocity vectors, the barycentric velocity, the diffusion velocities and the constituent strain rate tensors, respectively; $\mathbf{T}_{a}, \mathbf{m}_{a}, p$ are the partial Cauchy stress tensors, the constituent interaction forces, satisfying $\sum \mathbf{m}_{a}=0$, and the saturation pressure, a constraint variable, maintaining the saturation $\sum \boldsymbol{v}_{a}=1, v_{f}^{a}=1-v, \varepsilon_{a}, \varepsilon, \vartheta, \mathbf{q}$ are the constituent internal energies, the mixture internal energy, the Kelvin temperature (where $\vartheta_{0}=273.15 \mathrm{~K}$ ) and the heat flux vector, respectively. Moreover, in writing down equations (1)-(3) terms that are quadratic and of higher order in the velocities as well as accelerations (Stokes approximation) have been ignored. Dissipative mechanisms operate in the energy equation through the energy flux and the dissipative power of the stresses. Besides the conductive heat the energy flux vector $\mathbf{q}$ also contains contributions attributable as power of stresses working along the diffusive velocities and diffusively convected energy. Moreover, it is the power of the mixture stress expended on the stretching of the barycentric motion that incorporates implicitly the dissipation due to the Darcy forces.

\section{Boundary conditions}

The above equations must be complemented by boundary conditions. The physical nature of the problem we are dealing with implies that the boundaries of the till layer are free moving boundaries. As a consequence the balance and constitutive laws introduced in the previous section form, with the conditions we find in the present section, a free moving boundary problem which, to our knowledge, is new.

The top interface between the sediment water layer and the ice sheet is assumed to be material for the sediment, but allows for the water flux through it and melting of ice. As the latter is assumed to slide over the interface, this viscous process is a dissipative mechanism contributing to the melting of ice. The bottom interface is non-material for both constituents, as water can be drained into the rockbed and till abraded from it by sliding firiction, another dissipative mechanism of the sistem. These prerequisites determine the form of the kinematic surface conclition and the jump conditions of mass, momenta and the energy, holding at and across the surface, respectively.

At the ice/till-layer interface, the kinematic equation thus takes the form

$$
\frac{\partial f_{t} / \partial t}{\sqrt{1+\left|\nabla f_{t}\right|^{2}}}+\mathbf{w}_{t} \cdot \mathbf{n}=0
$$




\section{F. dell'Isola and $K$. Hutter}

where $x, y, z$ denote Cartesian coordinates and $z=f_{t}(x, y, t)$, is the equation of the top (index $t$ ) surface, while $\mathbf{n}$ is its unit normal pointing into the ice and $\nabla=\left(\partial_{x}, \partial_{y}\right)$. Alternatively, the jump conditions of mass, momenta and energy lead to the equations

$$
\begin{gathered}
\hat{\rho}_{f}(1-v)\left(\mathbf{v}_{f}-\mathbf{v}_{s}\right) \cdot \mathbf{n}=P_{f}+\mathscr{M}_{f} \\
\mathbf{T}_{s} \mathbf{n}=\alpha v(\mathbf{T n})_{\mathrm{ice}}, \quad \mathbf{T}_{f} \mathbf{n} \simeq(1-\alpha v)(\mathbf{T n})_{\mathrm{ice}} \\
\llbracket \varepsilon \rrbracket\left(P_{f}+\mathscr{M}_{f}\right)=\llbracket \mathbf{q} \cdot \mathbf{n}+\mathbf{v T} \cdot \mathbf{n} \rrbracket
\end{gathered}
$$

where

$$
\begin{aligned}
& |\varepsilon|=-L+\xi_{s}\left(\overline{\varepsilon_{f}}\left(\vartheta_{0}\right)-\varepsilon_{s}\left(\vartheta_{0}\right)\right)+\left[c_{i}-\left(1-\xi_{s}\right) c_{f}-\xi_{s} c_{s}\right]\left(\vartheta-\vartheta_{0}\right) \\
& \|\mathbf{q} \cdot \mathbf{n}\|=\left(\mathbf{q}_{\mathrm{them}}+\left(\left(k_{f}+k_{s}\right) \operatorname{grad} \vartheta\right)\right) \cdot \mathbf{n}+L^{+} \cdot \mathbf{n}+ \\
& \rho \xi_{s}\left(1-\xi_{s}\right)\left[\varepsilon_{f}\left(\vartheta_{0}\right)-\varepsilon_{s}\left(\vartheta_{0}\right)+\left(c_{f}-c_{s}\right)\left(\vartheta-\vartheta_{0}\right)\right]\left(\mathbf{v}_{f}-\mathbf{v}_{s}\right) \cdot \mathbf{n} \\
& +\left\{v(-\beta v+p)\left(\mathbf{v}_{s}-\mathbf{v}\right)-\left(\left(A_{s}\right)^{-\frac{1}{n}}\left(I I\left(\mathbf{D}_{s}^{\prime}\right)\right)^{-\frac{n-1}{2 n}} \mathbf{D}_{s}^{\prime}\right)^{T}\left(\mathbf{v}_{s}-\mathbf{v}\right)\right\} \cdot \mathbf{n} \\
& +\left\{(1-v) p\left(\mathbf{v}_{f}-\mathbf{v}\right)-\left(\mu_{f} \mathbf{D}_{f}^{\prime}\right)\left(\mathbf{v}_{f}-\mathbf{v}\right)\right\} \cdot \mathbf{n} \text {. } \\
& \left.\llbracket \mathbf{v T} \cdot \mathbf{n} \simeq \simeq \frac{\mathscr{C}_{t}}{\rho g} \frac{\left|(\mathbf{I}-\mathbf{n} \otimes \mathbf{n})(\mathbf{T n})_{\mathrm{ice}}\right|^{2}}{\left|\mathbf{n} \cdot(\mathbf{T} \mathbf{n})_{\mathrm{ice}}\right|^{2}} \llbracket(\mathbf{I}-\mathbf{n} \otimes \mathbf{n}) \mathbf{v}\right|^{2}
\end{aligned}
$$

Here the left hand side of equation (6) is the flow of fluid mass into the layer while $\mathscr{M}_{f}$ is the water flow from the ice onto, and $P_{f}$ is the mass of the ice melted at, the interface; the former is provided by the ice sheet and is here considered to be known, the latter follows as a result of the dissipation mechanisms of this theory. The tractions of the partial stresses on the layer side of the interface are given by the corresponding traction on the ice side with distributing factors $\alpha v$ and $(1-\alpha v)$, respectively, where $\alpha \simeq 1$. In the second equation of (7) the impulsive flux of water, which is very small, has been ignored. The energy jump condition (8) is the equation determining the melting rate of ice. Apart from a jump in energy flow explained above, it consists of a dissipation term due to sliding, which is quadratic in the tangential velocity jump, quadratic in the shear traction and inversely quadratic in the normal pressure. In (10) $\mathbf{j}^{+}$and $\mathbf{q}_{\text {therm }}$, respectively, denote the vector of moisture flux and of heat extraction from the ice sheet.

At the till-layer/rockbed interface, the kinematic equation can be written as

$$
\frac{\partial f_{b}}{\partial t}+\frac{1}{\tau_{v}}\left[f_{b}-\left(f_{b}^{0}-\frac{\rho_{i}}{\rho_{a}} H(x, y, t)\right)\right]=-\frac{\mathscr{M}_{s}^{b}}{\rho_{r}^{+}} \sqrt{1+\left|\nabla f_{b}\right|^{2}}
$$

where $z=f_{b}(x, y, t)$ is the equation of the bottom (index $b$ ) surface, $\rho_{r}, \rho_{i}, \rho_{a}$ are the densities of the ice, rock and asthenosphere, $H$ is the local thickness of the glacier, $f_{b}^{0}$ the relaxed position of interface without ice, $\tau_{v}$ the relaxation time with which the lithosphere-asthenosphere system reacts to the ice load and $\mathscr{M}_{s}^{b}$ is the abration rate of sediment mass from the sediment bed

$$
\mathscr{M}_{s}^{b}={ }_{s}^{b}|\tau|^{2}|\sigma|^{2}
$$


In the energy jump condition, since no phase change occurs, the jump $[\varepsilon]\left(\mathscr{M}_{f}^{b}-\mathscr{M}_{s}^{b}\right)$ is very small and may be ignored; thus the energy jump condition reduces to

$$
\llbracket \mathbf{q} \cdot \mathbf{n} \rrbracket=-\frac{\mathscr{C}_{b}}{\rho g} \frac{|\tau|^{2}}{\left.\sigma\right|^{2}} \mathbf{v}_{\|}^{2}
$$

In the above $\mathbf{n}$ is the unit normal vector pointing into the rockbed and

$$
\mathbf{v}_{\|}=(\mathbf{I}-\mathbf{n} \otimes \mathbf{n}) \mathbf{v}, \tau=(\mathbf{I}-\mathbf{n} \otimes \mathbf{n}) \mathbf{T} \mathbf{n}, \sigma=\mathbf{n} . \mathbf{T n}
$$

where $\mathbf{T n}$ is the total traction acting on the interface; $\mathscr{C}_{b}$ in equation (14) and $\mathrm{m}_{s}^{b}$ are two phenomenological coefficients. On the rock side of the bottom interface the heat flow normal to the bed is either prescribed as geothermal heat $(\mathbf{q} . \mathbf{n})_{\text {rock }}=-Q_{\text {geoth }}$, or computed from a thermal model of a layer of rock. We treat it here as known. Otherwise $[\mathbf{q} \cdot \mathbf{n} \rrbracket$ is given as stated in equation (10).

\section{Order of magnitude for the various dissipation phenomena}

Based on the well-known numerical values of the physical constants and on estimates of process quantities arising in the present formulation (the interested reader will find all of them collected in dell'Isola and Hutter, 1997) we will now give the orders of magnitude for the important dissipative terms. As for process quantity $v \in[0.5,0.85]$ we have $\xi_{s} \in[0.7,0.9]$. On the other hand the moisture content in ice is approximately $1-2 \%$ and the basal melting rate of ice is no more than approximately $5 \mathrm{mma}^{-1}=1.6 \times 10^{-10} \mathrm{~ms}^{-1}$ corresponding to $1.6 \times 10^{-7} \mathrm{kgm}^{-2} \mathrm{~s}^{-1}$.

Let us now turn to the energy jump condition (8) at the top interface. The dominant term of $\llbracket \varepsilon^{-1}$ in (9) is the latent heat of ice $L=3.35 \times 10^{5} \mathrm{Jkg}^{-1}$ with a comparable, but an order of magnitude smaller, contribution from the term $\zeta_{s}\left(\varepsilon_{s}\left(\vartheta_{0}\right)-\sigma_{f}\left(\vartheta_{0}\right)\right)$ of the same sign; the term in (9) involving the specific heats is about two orders of magnitude smaller, so that $[\varepsilon]=3.3 \times 10^{5} \mathrm{Jkg}^{-1}$. With the estimate of the melting rate of ice and the flow of moisture from the ice side to be of the order of $1.6 \times 10^{-7} \mathrm{kgm}^{-2} \mathrm{~s}^{-1}$, the left hand side of (8) yields

$$
[\varepsilon]\left(P_{f}+\mathscr{M}_{f}\right)=5.3 \times 10^{-2} \mathrm{Wm}^{-2}
$$

The two terms on the right hand side of (8) must have the same order of magnitude. As for $[\mathbf{q} \cdot \mathbf{n}]$, the conductive contribution is of the order of magnitude of the geothermal heat flow, which is approximately $5 \times 10^{-2} \mathrm{Wm}^{-2}$; the corresponding contribution in the ice can be ignored, because of the very small value of the Clausius-Clapeyron constant. Alternatively, taking an overly pessimistic value for the moisture diffusion velocity of $1 \mathrm{ma}^{-1}$ it can be easily shown that $L \mathbf{j} \cdot \mathbf{n}$ has an order of magnitude of $10 \mathrm{Wm}^{-2}$ which is not negligible. A typical component of the stress or pressure dependent term in (11) is $v p\left(\mathbf{v}_{s}-\mathbf{v}\right) \cdot \mathbf{n}$. Using $v \simeq 0.5, p \leq 2 \times 10^{7} \mathrm{~Pa}$ and an upper bound for the diffusion velocity given by $\mathbf{u}_{s} \cdot \mathbf{n} \leq 1 \mathrm{ma}^{-1}$ we obtain $\left|v p \mathbf{u}_{s} \cdot \mathbf{n}\right| \in\left[10^{-3}, 10^{-1}\right] \mathrm{Wm}^{-2}$ indicating that the omission of these terms may not be justified. Using the same estimate for the diffusion velocity $\mathbf{u}_{s} \cdot \mathbf{n}$ it may be concluded that $\left|\sum_{a} \rho_{a} \varepsilon_{a} \mathbf{u}_{a} \cdot \mathbf{n}\right| \in\left[10^{-2}, 10^{0}\right] \mathrm{Wm}^{-2}$. Thus, none of the terms in $\mathbf{q}$ ought to be ignored. Next, we need to estimate the stress power $\| \mathbf{v} \cdot \mathbf{T n}]$. With shear 


\section{F. dell'Isola and K. Hutter}

stresses as high as $10^{4} \div 10^{6} \mathrm{~Pa}$ and sliding velocities of $1 \div 10 \mathrm{ma}^{-1}$, we obtain $\left[\mathbf{v} \cdot \mathbf{T n} \in\left[\frac{1}{3} 10^{-3}, \frac{1}{3}\right] \mathrm{Wm}^{-2}\right.$ making the stress power equally significant. In summary, all terms in equations (8)-(11) contribute to the energy jump balance, except those involving the specific heats in (9). A similar analysis of order of magnitude estimates can also be performed with the energy jump balance (14), valid at the bottom interface, which is better written as $\langle\mathbf{q} \cdot \mathbf{n}=[\mathbf{v} \cdot \mathbf{T n}\rceil$. However, this is now straightforward: from the rockbed below we have the geothermal heat flow $4 \times 10^{-2} \mathrm{Wm}^{-2}$. On the layer side, there is no reason that the various contributions to $\mathbf{q} \cdot \mathbf{n}$ should not be of similar magnitude as those at the top interface. So the same terms as obtained above are important and contribute to the energy balance. Finally, as abrasion occurs, its contribution to the generation of heat is non-negligible and produces heat of a similar, if not higher, order of magnitude, as does the friction of ice over its bed. Thus, the term on the right hand side of (14) is very significant. We turn our attention next to the local energy balance. This equation must transport heat from the bottom interface to the top interface. If we envisage the dominant heat flow to be transverse to the interface, assume vector $\mathbf{q}$ to be between 1 and 10 times the geothermal heat flow and take a layer thickness of $5-10 \mathrm{~m}$ we obtain $\mid$ div $\mathbf{q} \mid \in\left[4 \times 10^{-3}, 8 \times 10^{-2}\right] \mathrm{Wm}^{-3}$. This number must be compared with the representative term in $\operatorname{tr}$ (TD). The dominant term of this must be $\tau \dot{\gamma}$, where $\tau$ is a representative shear stress and $\dot{\gamma}$ the corresponding shearing. With $\tau<10^{6} \mathrm{~Pa}$ and $\dot{\gamma} \sim v / H$, where $v \sim 100 \mathrm{ma}^{-1}$ and $H \sim 5 \div 10 \mathrm{~m}$ this yields $\tau \dot{\gamma} \in\left[10^{-2}, 10^{0}\right] \mathrm{Wm}^{-3}$.

Thus, we have made it plausible that all terms in the local energy balance and energy jump conditions contributing to dissipation must be accounted for.

Note remise le 20 septembre 1996, acceptée après révision le 15 avril 1997.

\section{References}

Alley R. B., Blankenship D. D., Bentley C. R., Rooney S. T., 1987a. Till beneath ice stream B, 3. Till deformation: evidence and implications, J. Geophys. Res., 92 (B9), 8921-29.

Alley R. B., Blankenship D. D., Bentley C. R., Rooney S. T., 1987b. Till beneath ice stream B, 4. A coupled ice-till flow model J. Geophys. Res., 92 (B9), 8931-40.

Buntenbarth G., 1980. Geothermie, Eine Einführung in die allgemeine und angewandte Wärmelehre des Ertk örpers, Hochschultext, Springer Verlag, Berlin.

dell'Isola F., Hutter K., 1997. What are the dominant thermomechanical processes in the basal sediment layer of large ice sheets? to appear in Proc. Roy. Soc. A London.

Germain P., Muller P., 1986. Introduction à la Mécanique des Milieux Continus, Masson, Paris.

Greve R., 1996. Application of a polythermal three-dimensional ice-sheet model to Greenland Ice Sheet: Response to steady-state and transient climatic scenarios, $J$. Climate (in press).

Mac Ayeal D. R., 1992. Irregular oscillations of the West Antartic Ice Sheet, Nature 359, 29-32.

Svensen B., Hutter K., 1995. On the thermodynamics of a mixture of isotropic materials with constraints Int. J. Engng Sci. 33, 14, $2021-2054$.

Truesdell C., 1969. Rational Thermodynamics, MacGraw-Hill, New York

Vulliet L., Hutter K., 1988. Set of constitutive models for soils under slow movement, J. Geotech. Engng, ASCE 1149 , 1022-1044. 